\title{
MULHERES NAS FORÇAS ARMADAS: UMA REFLEXÃO TEÓRICA
}

\section{WOMEN IN THE ARMED FORCES: A THEORETICAL REFLECTION}

\author{
Andréa Costa da Silva ${ }^{* \star}$ \\ Claudia Maria Sousa Antunes
}

Resumo: Este trabalho pretende empreender uma reflexão sobre a construção da identidade militar na contemporaneidade, investindo em teorizar sobre o momento histórico atual, marcado por transformações fazendo-nos perceber uma crise nas fontes tradicionais de referência de identidade (HALL, 2003), o que permite postular uma transformação das identidades de grupos tradicionalmente vistos como hegemônicos, como o militar (CASTRO, 2004). Essa abordagem leva a uma reflexão sobre a problemática da formação da subjetividade, e, consequentemente, sobre a ressignificação das questões de gênero em espaços anteriormente excluídos desta pauta, como as Forças Armadas. Desse modo, busca-se um olhar sobre o "modo de ser" dos militares, as suas tradições culturais, ou seja, sobre uma "maneira militar de agir", relacionado à integração feminina nos quartéis.

Palavras-chave: Gênero. Mulheres. Militar.

Abstract: This work intends to undertake a reflection on the construction of military identity in contemporary, investing in theorizing about the current historical moment, marked by transformations making us perceive a crisis in the traditional sources of identity reference (HALL, 2003), which allows to postulate a transformation of the identities of groups traditionally seen as hegemonic, as the military (CASTRO, 2004). This approach leads to a reflection on the problematic of the formation of subjectivity, and, consequently, on the resignification of gender issues in previously excluded areas of this agenda, such as the Armed Forces. In this way, a look at the military's "way of being", their cultural traditions, i. e., a "military way of acting", related to women's integration in the barracks.

Keywords: Gender. Women. Military.

\footnotetext{
* Versão atualizada do trabalho apresentado no Seminário Internacional Fazendo Gênero 11 \& 13th Women's Worlds.

Doutora e Mestre em Educação em Ciências e Saúde, pelo Programa de Pós - Graduação em Educação em Ciências e Saúde (NUTES / UFRJ), com especialização em Orientação Educacional pela FAHUPE e graduação em Direito pela Universidade Gama Filho. Atua como professora regente no magistério público desde 1985, a partir de 1996 no magistério público federal.

Possui graduação em Letras Português Literaturas pela Universidade Federal do Rio de Janeiro (1988), Mestrado em Letras (Letras Vernáculas) pela Universidade Federal do Rio de Janeiro (1997) e Doutorado em Letras (Letras Vernáculas) na Universidade Federal do Rio de Janeiro (2016). Atualmente, é Professora Adjunta da Universidade da Força Aérea (UNIFA) e pesquisadora do Núcleo de Estudos Interdisciplinares em Ciências Aeroespaciais (NEICA).
} 


\section{INTRODUÇÃO}

Em recente notícia ${ }^{1}$, uma revista on-line de grande circulação anunciou: "104 países proíbem a mulher, por lei, de fazer alguma coisa - e o Brasil está no grupo", o artigo explora aspectos do estudo "Mulheres, Empresas e Direito 2018" realizado pelo Banco Mundial que observa a legislação em 189 economias e mostra de que maneira ela impacta a vida das mulheres. Voltado à uma perspectiva econômica, o estudo pretende oferecer, no entanto, algo além, evidenciando: "Embora o acesso das mulheres ao emprego e a atividades empresariais esteja relacionado a muitos fatores, incluindo questões culturais, a legislação tem um papel importante nesse processo, podendo contribuir para a inclusão ou não das mulheres na economia", diz Paula Tavares, especialista em gênero e desenvolvimento econômico do Banco Mundial e responsável pelo relatório. Assim, podemos perceber que as questões culturais são indissociáveis da esfera legislativa que vigora em um país. Segundo evidencia também a notícia, no Brasil, as principais questões que restringem a ação das mulheres referem-se à violência e ao casamento infantil - dois entraves à independência financeira. Assim, o estudo analisa, que, embora o país tenha um arcabouço jurídico contra a violência, - como a Lei Maria da Penha, de 2006, por exemplo -, ainda existem lacunas e obstáculos na legislação que dificultam a proteção de mulheres e meninas ou sua plena integração na sociedade. A notícia ressalta também que "[...] as economias crescem mais rapidamente quando mais mulheres trabalham. "Isso reforça a ideia de que espaços mais igualitários são benéficos para toda a sociedade, em vários aspectos, até no econômico. Investindo em outra perspectiva, mas sem fugir ao tema, observamos que a abertura, constante e gradual, desde a década de 80, das Forças Armadas para a inserção feminina vem provocando debates sobre as consequências dessa integração. As novas configurações das sociedades e, em particular, da brasileira, leva-nos a questionar em que medida a inserção gradativa de mulheres em espaços que, até bem pouco tempo atrás, eram exclusivamente masculinos modificou os "modos de ser" e "modos de agir" de determinadas categorias profissionais. Segundo dados de 2016,

\footnotetext{
1 Disponível em: <https://epocanegocios.globo.com/Brasil/noticia/2018/06/104-paises-proibemmulher-por-lei-de-fazer-alguma-coisa-e-o-brasil-esta-no-grupo.html . Acesso em: 18/07/2018.
} 
o Brasil tem 25.898 mulheres nas Forças Armadas, entre Aeronáutica, Exército e Marinha. Elas constituem 7\% do efetivo total de defesa do País (MULHERES..., 2016), ou seja, a incorporação das mulheres nas Forças Armadas já se constitui uma realidade, apesar de ainda não ser efetiva em todas as áreas. Nessa perspectiva, é importante ressaltar a existência de leis como a 12.705/2012, promulgada pela presidente Dilma Rousseff, que dispõe sobre os requisitos para ingresso nos cursos de formação de militares de carreira do Exército. A lei contempla a possibilidade de formação de mulheres como oficiais de carreira combatentes e estabelece um prazo de cinco anos para que essa inclusão seja feita.

Ao analisar a legislação da Força Aérea Brasileira relativa ao envio de militares em operações de paz, sob a ótica das resoluções do Conselho de Segurança das Nações Unidas relativas ao tema "Mulheres, Paz e Segurança", Philippini (2016, p. 133), observa que:

Entre as disparidades encontradas no tratamento entre homens e mulheres na formação dos contingentes enviados para operações de paz, encontram-se as restrições de acesso a certas ocupações dentro da Força, como por exemplo, o impedimento do acesso feminino ao quadro Infantaria e a especialidades tais como Guarda e Segurança, Mecânica de Aeronaves e Material Bélico.

Ou seja, mesmo que inseridas dentro do meio castrense, as mulheres não estão em paridade de cargos e funções, apontando que as assimetrias de gênero continuam acontecendo e revelam distorções nas legislações, - e consequentemente no acesso - aos contingentes em que estão inseridas. Com isso, podemos perceber que, imbricadas nos entraves existentes às conquistas femininas, estão as visões e representações equivocadas sobre as potencialidades que o suposto "sexo frágil" poderia oferecer.

A transformação das identidades de grupos tradicionalmente vistos como hegemônicos, como o militar (CASTRO, 2004), nos leva a uma reflexão sobre a problemática da formação da subjetividade, com a consequente ressignificação das questões de gênero. As instituições militares, como categoria profissional específica, não devem ser compreendidas como uma construção estática e una, a não ser idealmente, construção essa necessária aos estudos científicos (CASTRO, 2004), já 
que existe a possibilidade de muitos "espíritos" formadores da identidade militar. Por outro lado, a construção de uma identidade profissional leva em conta os conceitos de unicidade da identidade e de pertencimento.

No caso das Forças Armadas, os militares são submetidos a uma série de normas, regulamentos e hierarquias que concorrem para a formação de um "dever ser" militar. Esse modo de ser caracteriza o espaço militar como marcado por tradições, convenções e assimetrias.

As mudanças efetuadas - por conta, entre outros fatores, da entrada das mulheres - nas corporações militares não são suficientes para modificar substancialmente a organização, mas são capazes de alterar aspectos organizacionais relacionados ao "ser militar" (D’ARAÚJO, 2004). Segundo essa autora,

Estas mudanças não significam, no entanto, transformações substantivas nos critérios de ação interna e de organização da instituição militar. Os princípios que tradicionalmente, regem as Forças Armadas são basicamente os da disciplina e da hierarquia. E, ao que tudo indica, assim continuará sendo na pós-modernidade." (D'ARAÚJO, 2004, p. 2)

A estruturação das relações militares (internas) é feita por meio da hierarquia (LEIRNER, 2001). Esse fato social total é um princípio formador da identidade militar. Assim, o debate sobre as carreiras militares, incluídas neste rol as funções de combate para as mulheres, é importante para que se possa compreender o gênero como um componente estruturador da experiência e das relações entre os sujeitos e, daí, sua implicação nas relações de dominação e de poder.

A seguir apresentamos alguns conceitos importantes para compreender 0 debate contemporâneo sobre a inserção feminina nas fileiras dos quartéis - com o mote de reflexão-, buscando contemplar aspectos relacionados à dinâmica cultural, tão afeitos ao tema em questão. 


\section{ENTRE $O$ ETHOS E A IDENTIDADE MILITAR: ESPAÇOS DE REPRESENTAÇÃO E (RE)SIGNIFICAÇÃO}

A noção de ethos militar relaciona-se ao "modo de ser" dos militares e às suas tradições culturais. Está relacionado a uma "maneira militar de agir", que compreende a aplicação de técnicas, a fim de se conseguir objetivos específicos. Esse conceito de ethos se aproxima, também, do conceito de habitus (BOURDIEU, 2007), que designa o estado de coisas que orienta a disposição e as ações dos indivíduos de forma durável, de modo a estes se adaptarem e viverem em um meio social.

$\mathrm{Na}$ perspectiva das Ciências Sociais, o ethos é considerado um termo genérico, relativo ao caráter cultural e social de um grupo ou sociedade. Ethos designaria os traços que diferenciam um grupo social de outro, sendo possível falar de um ethos do brasileiro em oposição a um ethos francês ou de um ethos militar em face de um ethos civil. O ethos "se desdobra, assim, como espaço da formação do hábito, entendido como disposição permanente para agir de acordo com os imperativos de realização do bem, tornando-se lugar privilegiado de inscrição da práxis humana." (RIBEIRO; LUCERO; GONTIJO, 2008, p. 127).

O ethos é um conceito híbrido, social/discursivo, ligado ao processo interativo de influência sobre o outro. Ele deve ser compreendido como pertencente a uma situação de comunicação específica, integrado a circunstâncias sóciohistóricas também específicas (MAINGUENEAU, 2007). Kerbrat-Orecchioni (1996 apud AUCHLIN, 2001) discute a ideia de associação entre a noção de ethos e os hábitos compartilhados pelos membros de uma comunidade linguística (AUCHLIN, 2001), segundo a autora:

\footnotetext{
Pode-se, com efeito, razoavelmente supor que os diferentes comportamentos de uma mesma comunidade obedecem a alguma coerência profunda e esperar que sua descrição sistemática permite apreender o "perfil comunicativo", ou ethos, dessa comunidade... (KERBRAT-ORECCHIONI, 1996, p. 78 apud AUCHLIN, 2001, p. 218).
}

Nesse sentido, é possível advogar uma relação entre o conceito de ethos e o conceito de estereótipo. Essa conexão aparece a partir do momento em que se pode 
afirmar que a estereotipagem "é a operação que consiste em pensar o real por meio de uma representação cultural preexistente, um esquema coletivo cristalizado" (AMOSSY, 2011, p. 125). Essa representação irá influir na avaliação pela qual o indivíduo passa na comunidade.

O mecanismo de estereotipagem origina-se no senso comum da sociedade e seu uso proporciona uma economia cognitiva por simplificar a complexidade de informações a que são submetidos os sujeitos. Por possuírem forte coloração afetiva, os estereótipos podem influenciar os processos de comunicação, pois todo sujeito está inserido em um mundo que é anterior a ele, e que contribui para a formação do seu pensamento.

O estereótipo também se caracteriza pela rigidez, pelo esquematismo, pela tonalidade avaliativa e pela especificidade. Assentados sobre sistemas de raciocínio e de linguagens, podem ser entendidos como um dos componentes da representação social. Essa representação está estruturada em modelos, em esquemas coletivos do setor da doxa ${ }^{2}$ em que estão situados. Alguns estereótipos ligam-se, em uma visão mais contemporânea, à construção da alteridade, já que as instituições e os sistemas de pensamento e de representação têm influência na regulação, segundo Jodelet (1998 apud ARRUDA; GONÇALVES; MULULO, 2008), das relações entre o eu e o outro.

Estereótipos e representações circulam na coletividade sob os mais diversos registros: pintura, escultura, teatro, cinema, publicidade. Sua análise permite perceber, entre outros aspectos, as maneiras pelas quais a doxa, o status quo é aceito ou contestado, e como as estruturas de poder e as relações sociais são concebidas. Com tais pressupostos, podemos pensar que a contemporaneidade se caracteriza por ser uma época de mudanças: tanto no sistema econômico - com mudanças decorrentes da globalização - quanto nas formas de pensar e construir conhecimento, o desenvolvimento de novas tecnologias e o acelerado processo de industrialização e de urbanização nos países ocidentais também contribuíram para esse novo quadro. Nesse contexto, a sociedade atual apresenta um quadro de transgressões e permanências. Como consequência, as mudanças se impõem e obrigam a uma reavaliação dos papéis masculinos e femininos. Essa modificação do

\footnotetext{
${ }^{2}$ Uma das propriedades de um campo específico, a opinião consensual (BOURDIEU, 1984).
} 
comportamento de homens e mulheres do século XXI favorece o estabelecimento de uma nova ordem social, com mudanças, às vezes sutis, outras mais marcantes, nos seus papéis.

É possível perceber a existência de uma mudança de padrões na cultura ocidental como fruto da ascensão social da mulher e das transformações culturais, sociais e econômicas atreladas à globalização. Esses aspectos influenciam na formação da identidade, entendida como o conjunto de aspectos específicos que configuram o indivíduo como agente sociocultural. Conforme o pensamento de Hall (2007), a identidade é uma construção política e cultural. Para esse autor, as identidades modernas vêm sofrendo um processo de "descentralização", de fragmentação, causado pelas mudanças na representação dos sujeitos provocadas pela globalização.

Castells (1999) propõe uma noção de identidade como o fruto de significados e experiências. Para esse autor, o processo de construção da identidade passa pela construção de um significado que está baseado em atributos culturais inter-relacionados. Esses atributos, inclusive, prevaleceriam sobre outras fontes de significado (CASTELLS, 1999, p. 22). Seriam as identidades as responsáveis pela fixação das bases do poder, organizando uma resistência na luta informacional e construindo novos comportamentos e instituições.

Parte-se, portanto, da ideia-base de que as sociedades pós-modernas estão passando por um processo de mobilidade da identidade, com a consequente (re)significação das relações identitárias, por conta, entre outras razões, da globalização. Essa descentralização das identidades (pós)modernas (HALL, 2007) possibilita a geração de identidades híbridas que são, em sequência, apreendidas pela mídia.

Além da criação de identidades híbridas, a fluidez identitária provocada pela permanente necessidade de adaptação (BAUMAN, 2008) gera uma "flutuação" das identidades (BAUMAN, 2005). Esse esgarçamento das relações na modernidade se reflete na composição do ethos das mais diversas categorias, sejam elas profissionais ou não. O ethos militar, nesse sentido, aparece como representativo das categorias consideradas relevantes para a comunidade em que se está inserido. A identidade social militar - entendida como o "espírito militar" - é concebida neste 
trabalho como o processo pelo qual passa o militar de forma a apreender os valores, as atitudes e os comportamentos julgados apropriados à vida na caserna.

\section{MULHERES E FORÇAS ARMADAS: MUITAS TRANSFORMAÇÕES?}

Os processos de transformação e conscientização da mulher, segundo Castells (1999), vêm provocando uma modificação nos modelos institucionalizados de família, com a contestação da estrutura patriarcal. O autor aponta, como forças motivadoras dessas modificações, as mudanças tecnológicas, as lutas femininas e o crescimento da economia global. Segundo Carvalho (1996, p. 23), "a sociedade de consumo identifica e reforça o papel feminino que vem se desenvolvendo historicamente a partir da organização patriarcal da sociedade, o de sustentáculo interno da estrutura familiar". Durante muito tempo, o papel da mulher estava voltado para o ambiente privado. Seu papel era o de mãe, dona de casa, filha, esposa. Essa imagem da mulher está relacionada à submissão e à ordem estabelecida dentro de uma ótica de sociedade patriarcal.

Essas visões autorizam o ponto de vista de que a inserção da mulher no mercado de trabalho e também sua participação como consumidora provocaram, com o passar do tempo, modificações na sua imagem. Essa nova situação fez surgir contradições na condição da mulher na atualidade, como a concomitância de atribuições no desempenho de seus vários papéis na sociedade. Essa multiplicidade de competências também aparece como um fator na mudança da imagem feminina. Um dos aspectos diz respeito às questões da maternidade. Esse tópico aparece com frequência quando o assunto é a presença da mulher nas Forças Armadas. Muitos pesquisadores já apontaram que este é um enfoque considerado, pelo menos por certas instâncias do ambiente militar, como inerente à mulher, e que isso comprometeria o desempenho feminino no front, apesar do estatuto da maternidade estar, também, em mudança, com novas configurações (tanto de maternidade quanto de paternidade) se consolidando.

A presença das mulheres no meio castrense vincula-se ao ambiente de transformações nos papéis sociais atribuídos aos homens e mulheres, em especial ao processo de inserção feminina em corporações exclusivas ao gênero masculino. 
As mulheres, hoje, ocupam espaços na política, no trabalho, na guerra. Saíram do espaço puramente privado para os espaços públicos, e isso traz reflexos nas múltiplas interações com as quais elas têm que lidar. Essa participação feminina nas várias esferas da sociedade altera as relações de poder no mundo do trabalho, da educação e de todas as outras áreas em que se insere. Com a sua inserção nas fileiras militares não poderia ser diferente.

Com a acepção de Joan Scott (1995) teorizamos sobre este cenário considerando o conceito de gênero, como: "[...] elemento constitutivo das relações sociais fundadas sobre as diferenças percebidas entre os sexos, e um primeiro modo de dar significado às relações de poder." (SCOTT, 1995, p. 77). Scott diz ainda:

[...] o gênero implica quatro elementos, a saber: a) símbolos culturalmente disponíveis, que evocam representações simbólicas, mesmo contraditórias, como Eva e Maria na tradição cristã; b) conceitos normativos que limitam os sentidos metafóricos atribuíveis aos símbolos. Estes se expressam nas doutrinas que regem os diversos campos institucionais - religião, educação, ciência, política afirmando de forma categórica e sem equívocos o sentido do masculino e do feminino; c)a aparência de consenso e de fixidez pela qual são veiculadas essas posições normativas; d) a identidade subjetiva. O gênero se constrói para além da família e das relações de parentesco. (SCOTT, 1995, p. 86)

Pensando com a autora, podemos considerar que, enquanto homens e mulheres, estamos incorporados a processos de naturalização de atribuições sociais, vivenciados no quotidiano. A introjeção dessa estrutura pela nossa subjetividade marca cada atuação social própria e em relação ao outro, pois define nossos modos de perceber o mundo, interpretar a cultura e estabelecer parâmetros de relacionamento. A importância de perceber a dinâmica dos elementos descritos por Scott incide em despolarizar construções estáticas e reconhecer a participação do processo de produção simbólica como elemento dinâmico. As relações sociais vão colaborar para o processo de subjetivação e construção de identidade em cada indivíduo. Assim, devemos sempre levar em conta instâncias como a família, o trabalho, os meios de comunicação e o contexto cultural como lugares de circulação e produção simbólica. Neste sentido, utilizamos o conceito de gênero em seu caráter relacional, referindo-se ao modo como as características sexuais são 
compreendidas e representadas, visando "rejeitar um determinismo biológico implícito no uso dos termos como sexo ou da diferença sexual" (SCOTT, 1995, p. 72). Deste modo, seria simplista perceber este movimento de maneira polarizada; muito mais interessante será pensar a natureza relacional do poder.

Considerando tais pressupostos, observamos o papel das mudanças, sejam elas sociais ou tecnológicas, na participação de mulheres nas Forças Armadas, já abordado por diversos estudiosos do tema, como Segal (1995) e Carreiras (2006). Gomes, ao abordar a questão da "mulher militar", afirma:

[...] são três os principais fatores que levam à integração das mulheres às Forças Armadas. O primeiro é a democracia que cada vez mais exige maior igualdade na oferta de oportunidades para os cidadãos. Depois, está a mudança na forma de fazer a guerra, nisto compreendendo as mudanças tecnológicas (sofisticação nos armamentos) e administrativas (gestão da guerra). O terceiro fator chamado psicossocial, é consequência da percepção dos agentes sobre a função dos militares, o que englobaria a questão econômica (proventos e benefícios) e também o prestígio da profissão, resultante tanto do grau de legitimidade castrense (crise de identidade e grau de confiança da sociedade) como da pouca atração que a profissão teria para o sexo masculino. (GOMES, 2012, p. 1832)

As restrições à presença da mulher em algumas posições militares vêm caindo com o passar do tempo. Apesar de ainda haver um debate intenso em alguns setores, na maioria dos países ocidentais já é rotineira a entrada de mulheres nas fileiras. Nesse âmbito, os argumentos contra a inserção feminina se baseiam na ideia de que a mulher seria um ser que deveria ser protegido, e esse pensamento faria com que fossem excluídas de certas atividades militares consideradas de alto risco, pois, nessas situações, o militar do sexo masculino tenderia a "proteger" a mulher, em detrimento da missão.

Em relação ao nível institucional, os obstáculos para a admissão de mulheres relacionam-se, basicamente, aos papéis sociais exercidos por homens e mulheres na sociedade e, também, a certas características consideradas como da essência feminina ou masculina. Esses valores, marcadamente culturais, interferem, juntamente com outros fatores, na explicação para a disponibilidade, ou não, de mulheres em posições notadamente operacionais nas Forças Armadas. Para 
Carreiras (2013, p. 480): “[...] boa parte dos obstáculos que persistem ao nível institucional remetem para o plano dos valores culturais sobre a 'natureza' e os papeis sociais de homens e mulheres, refletindo-se claramente no debate sobre a participação militar feminina e a eficácia militar. "Sobre os valores culturais, estes têm grande influência sobre o viés pelo qual as discussões ocorrem.

\section{CONSIDERAÇÕES FINAIS}

Com este artigo pretendemos oferecer breve reflexão sobre aspectos contemporâneos acerca da inserção feminina em espaços armados. Acreditamos que, ao trazermos luz sobre questões como identidade, ethos e as representações em vários contextos, estamos contemplando a dinâmica cultural, por vezes negligenciada nas legislações que amparam o contingente feminino presente nos quartéis, bem como podemos levantar perspectivas e desafios à entrada feminina nos espaços armados. A promulgação de leis como a sancionada em 2012, que estimula a entrada de mulheres na linha bélica, e o foco no desempenho são movimentos relevantes para o aumento contínuo da presença feminina nos quartéis.

A teorização sobre o tema remete às questões presentes no quotidiano dos quartéis e a parcela significativa do contingente nas Forças, conforme evidenciamos. Embora possamos perceber que as percepções sobre as questões relativas à entrada das mulheres nas Forças Armadas são socialmente construídas, a posição feminina aparece relacionada à formação do pensamento de cada cultura sobre o que é "ser mulher" e, também, do que é "ser militar".

Distante de ser um campo estabilizado, as conquistas femininas são constante espaço de luta e tensionamento; seja pela democratização das sociedades, seja pela busca pelo igualitarismo étnico, de credo ou de gênero, seja pela mudança nas formas da guerra, essa integração vem galgando degraus importantes, mas ainda há um longo caminho a ser percorrido.

Avanços no reconhecimento do potencial feminino para atuação em outros espaços sempre serão notícias bem-vindas se vislumbrarmos a questão da igualdade de gênero na sociedade. No entanto, as conquistas grupais devem ser consideradas sem deixar de lado outras questões que podem comprometer a 
individualidade de cada um. Homens e mulheres, antes de pertencerem aos grupos sociais a que estão agregados, devem ser considerados em sua autonomia individual. Ou seja, no embate entre a dimensão individual e a dimensão grupal, existem aspectos que por vezes estarão circunscritos a tensões, mas que não são identidades opostas e excludentes. E, desse modo, a questão de se discutir toda a dinâmica das relações de gênero e dos processos de identidade e diferença não diz respeito apenas a garantir a "não violência contra as mulheres" ou " a inserção feminina nos quartéis", trata-se de uma questão bem mais complexa que inclui as mencionadas, mas que não se esgota nelas.

\section{REFERÊNCIAS}

AMOSSY, Ruth. Da noção retórica de ethos à análise do discurso. In: AMOSSY, R. (Org.). Imagens de si no discurso: a construção do ethos. São Paulo: Contexto, 2011. p. 9-28.

ARRUDA, Ângela; GONÇALVES, Luana Pedrosa Vital; MULULO, Sara Costa Cabral. Viajando com jovens universitários pelas diversas brasileirices: representações sociais e estereótipos. Psicol. estud.: online, v.13, n.3, p. 503-511, 2008. Disponível em: <http://www.scielo.br/pdf/pe/v13n3/v13n3a11.pdf>. Acesso em: 14 fev. 2014.

AUCHLIN, Antoine. Ethos e experiência do discurso: algumas observações. In: MARI, Hugo; MACHADO, Ida Lúcia; MELO; Renato de (Org.) Análise do discurso: fundamentos e práticas. Belo Horizonte: Núcleo de Análise do Discurso FALE/UFMG, 2001.

BAUMAN, Zygmunt Identidade. Rio de Janeiro: Jorge Zahar, 2005.

Vida para Consumo: a transformação das pessoas em mercadoria. RJ: Jorge Zahar, 2008.

BOURDIEU, P. A economia das trocas simbólicas. 5 ed. São Paulo: Perspectiva, 2007.

Homo academicus. Paris, Editions de Minuit, 1984.

BRASIL. Lei no 12.705, de 08 de agosto de 2012. Dispõe sobre os requisitos para ingresso nos cursos de formação de militares de carreira do Exército. Brasília, DF, 2012. Disponível em: <http://www.planalto.gov.br/ccivil_03/_ato20112014/2012/lei/l12705.htm>. Acesso em: 14 mai. 2018. 
CARREIRAS, Helena. Gender and the Military: Women in the Armed Forces of Western Democracies. Londres, Routledge, 2006.

. Mulheres, direitos e eficácia militar: o estado do debate. Revista Militar, Lisboa, n. 2536, maio 2013. Disponível em:

<http://www.revistamilitar.pt/artigo.php?art_id=826.>. Acesso em: 28 jun. 2017.

CARVALHO, N. Publicidade: a linguagem da sedução. São Paulo: Ática, 1996.

CASTELLS. Manuel. Paraísos comunais: identidade e significado na sociedade em rede. In.: 0 poder da identidade. Tradução: Klauss Brandini Gerhardt. 2. ed. São Paulo: Paz e terra, 1999. (A era da informação: economia, sociedade e cultura, 2).

CASTRO, Celso. 0 espírito militar: um antropólogo na caserna. 2 ed. rev. Rio de Janeiro: Zahar, 2004.

D'ARAÚJO. Maria Celina. Mulheres e questões de gênero nas Forças Armadas brasileiras. Resdal: Red de Seguridad y Defensa de América Latina, Buenos Aires, 2004. Disponível em: <http://www.resdal.org/producciones-miembros/redes-03daraujo.pdf>. Acesso em: 29 jun 2017.

FREITAS, Luís. Escola do Exército abre $1^{\underline{a}}$ turma de cadetes mulheres e restringe namoro. Folha de São Paulo, Cotidiano, 26 set. 2016. Disponível em: <http://www1.folha.uol.com.br/cotidiano/2016/09/1816549-escola-do-exercito-abre-1turma-de-cadetes-mulheres-e-restringe-namoro.shtml >. Acesso em: 22/03/2017.

GRISOTTO, Raquel. 104 países proíbem a mulher, por lei, de fazer alguma coisa: e o Brasil está no grupo. Época Negócios, 15 jun. 2018. Disponível em: $<$ https://epocanegocios.globo.com/Brasil/noticia/2018/06/104-paises-proibemmulher-por-lei-de-fazer-alguma-coisa-e-o-brasil-esta-no-grupo.html>. Acesso em: 17 jul. 2018.

GOMES, Julio Cesar. O corpo feminino no corpo de tropa: existe mulher militar? In: ENCONTRO NACIONAL DA ASSOCIAÇÃO BRASILEIRA DE ESTUDOS DE DEFESA, 6. 2012, São Paulo. Anais eletrônicos... São Paulo: UNESP, 2012. p.1832. Disponível em: <https://www.abedef.org/download/download?ID_DOWNLOAD=74>. Acesso em: 02 ago. 2018. p. 1830-1841.

HALL, S. A identidade cultural na pós-modernidade. Tradução: Tomaz Tadeu da Silva; Guacira Lopes Louro. Rio de Janeiro: DP\&A, 2003.

. Quem precisa de identidade? In: SILVA, T. T. (Org). Identidade e diferença: a perspectiva dos estudos culturais. 7 ed. Petrópolis: Vozes, 2007.

KERBRAT-ORECCHIONI, Catherine. O ethos em todos os seus estados. In: MACHADO, Ida Lúcia; MELLO, Renato de (Org.). Análises do discurso hoje. Rio de Janeiro: Nova Fronteira, 2010. v. 3. 
LEIRNER, Piero C. O sistema da guerra: uma leitura antropológica dos exércitos modernos. 2001. Tese (doutorado em Antropologia Social). São Paulo, Departamento de Antropologia, Universidade de São Paulo/USP, 2001.

LIMA, Ludmilla de. Moradoras do Rio são promovidas à patente de Coronel do Exército. O Globo, Rio de janeiro, 18 jun. 2017. Disponível em:

$<$ https://oglobo.globo.com/rio/moradoras-do-rio-sao-promovidas-patente-de-coroneldo-exercito-21489581>. Acesso em: 28 jun 2017.

MAINGUENEAU, Dominique. A propósito do ethos. In: MOTTA, Ana Raquel; SALGADO, Luciana (org.). Ethos discursivo. São Paulo: Contexto, 2007. p. 11-29.

MULHERES vencem resistências históricas e conquistam espaço nas Forças Armadas: elas já são quase 26 mil oficiais na Aeronáutica, Exército e Marinha; conheça algumas dessas mulheres. Governo do Brasil, Cidadania e Justiça, n. 3, 2016. Disponível em: <http://www.brasil.gov.br/cidadania-ejustica/2016/03/mulheres-vencem-resistencias-historicas-e-conquistam-espaco-nasforcas-armadas>. Acesso em: 6 fev. 2017.

PHILIPPINI, Renato Augusto de Alcântara. Força aérea brasileira: mulheres, paz e segurança. 2016. 205 f. Dissertação (Mestrado em Ciências Aeroespaciais) Universidade da Força Aérea, Rio de Janeiro, 2016.

RIBEIRO, Lucas Mello Carvalho; LUCERO, Ariana; GONTIJO, Eduardo Dias. O ethos homérico, a cultura da vergonha e a cultura da culpa. Psychê: online, v. XII, n. 22, jan./jun. 2008. Disponível em:

<http://www.redalyc.org/articulo.oa?id=30711292010 >. Acesso em: 28 abr 2015.

SCOTT, Joan. Gênero: uma categoria útil de análise histórica. Recife: SOS Corpo, 1995.

SEGAL, Mady Wechsler. Women's Military Roles Cross-Nationally: Past, Present, and Future. Gender and Society, n. 9, v. 6, p. 757-775, 1995. 